\title{
Did You Sleep Well, Darling?-Link between Sleep Quality and Relationship Quality
}

\author{
Angelika Anita Schlarb1 ${ }^{*}$, Merle Claßen1, E.-S. Schuster², Frank Neuner1, \\ Martin Hautzinger ${ }^{2}$ \\ ${ }^{1}$ Faculty of Psychology and Sports, University of Bielefeld, Bielefeld, Germany \\ ${ }^{2}$ Faculty of Science, University of Tuebingen, Tuebingen, Germany \\ Email: *angelika.schlarb@uni-bielefeld.de
}

Received 2 November 2015; accepted 26 December 2015; published 29 December 2015

Copyright (C) 2015 by authors and Scientific Research Publishing Inc.

This work is licensed under the Creative Commons Attribution International License (CC BY). http://creativecommons.org/licenses/by/4.0/

(c) (i) Open Access

\begin{abstract}
Background: Relationship quality and sleep quality influenced physiological and psychological health. Therefore, the aim of the present study was to determine a possible connection between relationship satisfaction and sleep quality and to test a theoretical model of sleep quality as related to relationship and psychological well-being. Methods: Fifty-one heterosexual, cohabitating couples between 24 and 70 years old participated. The relationship quality was measured by the German short version of relationship questionnaire. To determine the sleep quality, the Pittsburgh Sleep Quality Index and a two-week sleep diary were implemented. To gather information about psychological well-being, especially depression and anxiety, the German Symptom Checklist was used. Results: Sleep quality was measured by the Pittsburgh Sleep Quality Index and relationship quality correlated significantly negative. In addition, the study found a positive correlation between sleep duration and relationship quality. In a multiple regression model, fighting and mental strain explained $38 \%$ of variance of sleep quality. Depression, anxiety and relationship quality showed no further improvement of the model. These findings suggested that relationship quality, constructive partnership behavior and mental strain played an essential role in sleep quality.
\end{abstract}

\section{Keywords}

Relationship Quality, Cohabitating Couples, Sleep Quality, Fighting, Mental Health

\section{Introduction}

Both relationships and sleep have a high impact on quality of life and well-being [1]. As sleep and relationships

\footnotetext{
"Corresponding author.
}

How to cite this paper: Schlarb, A.A., Claßen, M., Schuster, E.-S., Neuner, F. And Hautzinger, M. (2015) Did You Sleep Well, Darling? - Link between Sleep Quality and Relationship Quality. Health, 7, 1747-1756. 
are connected with well-being [2] [3] and sleep is typically shared within close relationships [3], it is easily deduced that sleep, relationship quality and mental health are strongly associated. Sleep is commonly seen as a critical health behavior linked with much morbidity via various physiological and psychological mechanisms. Due to the subjective importance, relationships influence mental health. But mental health also has a high impact on relationship quality [4].

\subsection{Sleep and Relationship Satisfaction}

A large Korean longitudinal study showed a bidirectional association between sleep and relationship quality. Low marriage quality led to a higher risk of a clinically relevant sleep disorder. Vice versa, a low sleep quality in the early stages predicted lower marriage satisfaction four years later [5]. Sleep duration seemed to be influenced by relationship status, as singles and divorced people sleep less than married participants [2]. Furthermore, unmarried people were more at risk of sleep disturbances compared to married adults [6]. Haslers and Troxel assessed couples about sleep and relationship functioning [7]. In men, higher sleep efficiency (measured by sleep diary) had a predictive value on less negative interaction with the partner. Vice versa, positive interactions reported by women seemed to influence men's sleep efficiency positively.

Various mechanisms might explain the association between relationship quality and sleep. For example, attachment styles impacted sleep in married couples [8]. Individuals reporting higher scores in fear of attachment had a decreased sleep quality. Furthermore, couples being physically apart reported increased sleep problems in nights they spent without their partners [9]. In addition, women in happy relationships seemed to have no sleep difficulties, whereas women with sleep problems reported less satisfaction with their marriages [10]. Cacioppo and colleagues [11] investigated the influence of loneliness on sleep. They found a relationship between loneliness and sleep efficiency, stating that people who felt lonely had lower sleep efficiency (83\%) than people who did not (90\%). Relationship status seemed to influence sleep in women, especially [3]. Comparing 367 middleaged women longitudinally for eight years in terms of relationship status and sleep quality measured by polysomnography, questionnaires and actigraphy, they found significant differences between women in a consistent marriage and women who had lost their partners. Married women had shorter phases of nightly awakenings than women who lost their partners or had never been married. Women who lost their partners had poorer sleep quality. Women who had never been married had longer sleep latency than married women. In men, no comparable studies were available.

Mental illnesses could influence the partner's sleep as well. For example, partners reported shorter sleep duration if their spouses suffered from anxiety. But depressive husbands led to longer sleep durations in women [12].

Intimate partner violence also influenced sleep quality [13] [14]. A bidirectional association of sleep on intimate partner violence and vice versa was found in couples living together and having at least one child [14]. Furthermore, psychological violence predicted sleep problems two years later, mediated by depression and anxiety [13].

\subsection{Relationship Quality}

Investigating long term influences on relationships Orbuch and colleagues found only ethnicity and educational status to be significant predictors on divorces over a duration of 14 years [15]. A lower educational level and African-American race tend to predict a divorce. Furthermore, with increasing age, satisfaction within the relationship decreases [1]. Conflict behavior seems to play an important role in relationship satisfaction [16]. Destructive behavior such as screaming, insulting and disdainfulness is associated with divorces one year after marriage. Even if one partner behaves constructively and the other's reaction is withdrawal, risk for divorce increases. Nevertheless, fighting alone does not account for relationship satisfaction. Tenderness seems to be more important than the absence of conflicts [1].

Beyond that, the regularity of sexual intercourse influences relationship satisfaction as reported in a multiple regression. Results suggest younger women are more satisfied with sexual intercourse than older women. Younger women tend to be slightly more satisfied with their relationships in general [17].

\subsection{Sleep and Mental Health}

Taylor and colleagues found a connection between sleep, depression and anxiety [18]. Participants with insomnia reported significant depression and anxiety scores. Furthermore, functional impairments such as reduced 
self-care, mobility, cognition, social functioning, time out of role and components of productive role functioning have been studied in people suffering from insomnia with comorbidities [19]. Neckelmann, Mykletun and Dahl surveyed participant's anxiety, depression and insomnia twice in 11 years [20]. Longitudinal data showed that participants with insomnia were at higher risk to develop depression and anxiety later on. Zawadzki and colleagues [21] investigated the influence of rumination and the feeling of loneliness on sleep. Their data suggests that loneliness and depression lead to poorer sleep quality. Supporting this, as soon as the feeling of loneliness decreases, symptoms of anxiety and rumination improve [21].

\subsection{Other Variables Influencing Sleep}

Stress negatively influences sleep as Vahtera and colleagues [22] showed in a longitudinal study performed. All stressful events were predictive for sleep disorders. Despite that, patients suffering from insomnia often report significantly more stressful and negative events than healthy sleepers [23]. Furthermore, arousal and coping strategies mediated the stress' influence on sleep, in patients with insomnia and healthy sleepers [23].

In addition age and gender influence sleep. Higher age seems to be associated with sleep disorders as more women over 60 suffered from disturbed sleep (31.4\%) about twice as many as women between 18 and 39 (17.9\%). For men the rate was even three times higher. Between the age of 18 and 39 years about $9.5 \%$ reported sleep disturbances, where as nearly one third of men above 60 years showed sleep disorder symptoms (29.0\%) [24].

As relationships and sleep seem to influence quality of life and health, the present study's aim is to determine the link between sleep quality and relationship quality. Firstly, it is assumed that (1) women report subjectively poorer sleep quality than men. Women tend to suffer from more difficulties falling asleep and maintaining sleep. Secondly, (2) psychological well-being is associated with sleep quality in both sexes, since previous studies reported overall mental health, depression and anxiety to be associated with sleep disturbances. Thirdly, (3) sleep quality and relationship quality is correlated. Low relationship quality is associated with low sleep quality. Fourthly, (4) fighting in intimate relationships seems impact sleep negatively. Finally, (5) a theoretical model including relevant factors will be tested. The influence of partnership quality, fighting and mental health on sleep quality will be investigated.

\section{Materials and Methods}

\subsection{Procedure}

Participants were recruited in public presentations and hearings at Landau University. All participants were informed prior to their participation about the content and duration of the study and gave their written consent. Furthermore, the Ethics Committee University of Landau permitted the study. Participants took part voluntarily. The participants filled out three questionnaires and recorded on their sleep for one week. After filling out the questionnaire, participants mailed them back via postal sending. Inclusion criteria were that couples cohabitated and both partners filled out the questionnaires.

\subsection{Questionnaires}

\subsubsection{Pittsburgh Sleep Quality Index (PSQI)}

The Pittsburgh Sleep Quality Index (PSQI) was implemented to assess sleep problems. 18 items (ranging from 0 to 3) measure self-rated sleeping habits within the last four weeks. The items are divided into seven scales, sleep quality, sleep latency, sleep duration, habitual sleep efficiency, sleep disturbances, use of sleep medication and daytime dysfunction. A total sum score is built with a cut-off score above five indicating bad sleepers and a score above 10 suggesting severe sleep problems [25].

\subsubsection{Sleep Diary}

In addition, a standardized sleep-diary was used for diagnostics for 14 days. Every day, participants answered questions about the time they went to bed, when they got up and their latency to fall asleep. There were open questions about the amount of exercise, intake of medicine (type, dose and time), as well as consumption of alcohol, nicotine and caffeine. Subjective measures of mood, sleepiness and performance were rated in a scale from one (very good) to six (very bad). The diary compromised a morning and an evening component. The 
morning section should be completed immediately after getting up and consists of 12 items. The nine items of the evening component should be done just before turning off the light. Additionally dichotome items (yes or no) about sexuality, tenderness and fights were generated.

\subsubsection{Partnership}

To evaluate partnership quality, a short version of a relationship questionnaire was used [26]. This German questionnaire (PFB-K) consists of nine items (ranging from 0 to 3), which are divided into three scales, fightingbehavior (coded inversely), tenderness and commonality. In a tenth item the happiness of the relationship was rated. A sum score is generated. A score lower than 17 means an unhappy relationship. Two additional items were generated, concerning sex and satisfaction with sex.

\subsubsection{Symptom-Checklist (SCL-90-R)}

For mental health the symptom-checklist (SCL-90-R) [27] measured subjective impairment by physiological and psychological symptoms. In 83 items aspects about somatization, obsessive behavior, social phobia, depression, anxiety, aggression, phobic anxiety, paranoid thoughts and psychoticism were quantified. There are seven additional items. Via a calculated sum score a comparison to a validation sample can be done. In the present study the sum score and the scales depression and anxiety have been used.

\subsection{Data Analysis}

The statistical analysis was calculated with IBM SPSS 21 for Windows. Pearson correlations were calculated to determine associations and t-tests were performed to test differences between genders. To investigate the influence of age, well-being and relationships on sleep parameters, a linear regression was performed. A multifactorial variance analysis was performed to identify different factors explaining sleep quality.

\section{Results}

\subsection{Subjects}

Seventy-one couples received questionnaires with 68\% mailing them back. Data analysis included a total of 102 participants $(n=102)$, or 51 heterosexual couples. The couples' age ranged between 24 and 70 years $(M=42.37$, $\mathrm{SD}=14.18)$. For further information see Table 1 .

All couples cohabited between 6 months and 44 years. Twenty-five (24.5\%) participants had children living with them, whereas 35 (34.3\%) had children, who were not living with the many more. Most of the participants had a fulltime job (54.9\%). For further information see Table 2.

Table 1. Demographic data.

\begin{tabular}{cccc}
\hline & Male M (SD) & Female M (SD) & Couples M (SD) \\
\hline age & $43.76(14.52)$ & $40.98(13.82)$ & $42.37(14.18)$ \\
Time as a couple & & & $16.02(14.19)$ \\
\hline
\end{tabular}

Note: $\mathrm{M}=$ mean; $\mathrm{SD}=$ standard deviation.

Table 2. Descriptive statistics of the couples: number of children, medication intake, profession.

\begin{tabular}{|c|c|c|c|}
\hline & & Frequencies & Percent \\
\hline \multirow{3}{*}{ Children } & None & 42 & 41.2 \\
\hline & Living at home & 25 & 24.5 \\
\hline & Not living at home & 35 & 34.3 \\
\hline \multirow{2}{*}{ Medication } & Yes & 35 & 34.3 \\
\hline & No & 67 & 65.7 \\
\hline \multirow{5}{*}{ Profession } & None & 7 & 6.9 \\
\hline & Retirement & 9 & 8.8 \\
\hline & Full-time & 56 & 54.9 \\
\hline & Part-time & 19 & 18.6 \\
\hline & University student & 11 & 10.8 \\
\hline
\end{tabular}




\subsubsection{Sleep Characteristics}

According to the PSQI, in mean the sample reported marginally poor sleep $(M=5.21$; $S D=2.70)$. Overall, the participants (76.5\%) needed up to 30 minutes to fall asleep (sleep latency PSQI-score; range 0 - 3: $\mathrm{M}=0.98$, SD $=0.89$ ) and slept for more than seven hours in mean (sleep duration PSQI-score; range $0-3: \mathrm{M}=0.46$, $\mathrm{SD}=$ $0.76)$.

In the morning participants rated their mood in the sleep diary and in mean their mood was fairly good (range 1 - 6, $M=2.55 ; \mathrm{SD}=0.64$ ). Furthermore, participants felt fairly fresh in the mornings (range 1 - 6, $M=2.93$; $\mathrm{SD}=0.77)$. In mean, participants fell asleep after 14 minutes $(\mathrm{M}=13.96$; $\mathrm{SD}=12.52)$. But sleep latency ranged between zero and 95 minutes. Only $4.9 \%$ needed more than 30 minutes to fall asleep and would therefore lie above clinical cut-off according to the DSM-5. Participants reported in mean 7.12 hours sleep with nightly awakenings occurring for 1.16 minutes on average. No participants experienced awakenings at night lasting longer than 30 minutes. Overall, participants were physically active for 67.73 minutes $(S D=73.53)$ per day. Couples reported close to no fights $(\mathrm{M}=0.085$; $\mathrm{SD}=0.14)$. Zero to $10(9.8 \%)$ reported a fight with the partner on any morning/evening protocol. Eight (7.8\%) to 21 (20.6\%) participants reported sexual intercourse per day. Forty (39.25\%) to $82(80.4 \%)$ reported tenderness.

\subsubsection{Well-Being}

Overall, the sample was mentally sane, as measured by the SCL-90-R (GSI t-transformed M = 50.51; SD = 9.44).

\subsubsection{Relationship Characteristics}

In mean the participants reported happy relationships above the cut-off (sum score $>17$ ) for a satisfying relationship ( $\mathrm{M}=18.52$; $\mathrm{SD}=4.70)$. 26.5\% of all participants showed a sum score of 16 or lower and seemed unhappy in their relationship. The mean for fighting behavior is $M=6.98(S D=1.95)$, for tenderness $M=5.76$ ( $\mathrm{SD}=2.24)$ and for communality $\mathrm{M}=5.80$ ( $\mathrm{SD}=1.65)$. All above cut-off $(<5.66)$, suggesting good relationships in all areas. Most couples considered sexual intercourse important in their relationship (range $0-3 ; \mathrm{M}=$ 1.91; SD = 0.72), with higher scores indicating higher subjective importance. Furthermore, satisfaction with their inter course seemed common (range 0-3; $\mathrm{M}=1.87$; $\mathrm{SD}=0.67$ ).

\subsubsection{Demographic Variables and Sleep}

Age and sleep duration correlated significantly $(r=-0.402, p=0.000)$ as older people slept less and age explains $16 \%$ of the variance. In a regression of daytime sleepiness and age, $5 \%$ of daytime sleepiness variance was explained by higher age. No other variables of the PSQI showed an association with age.

Gender had a significant influence on sleep latency $(p=0.037)$ and sleep duration $(\mathrm{p}=0.049)$ with woman needing more time to fall asleep $(\mathrm{M}=16.55$; $\mathrm{SD}=15.76)$ than men $(\mathrm{M}=11.38$; $\mathrm{SD}=7.47)$. Furthermore, women slept longer $(M=7.28$; $\mathrm{SD}=0.81)$ than men $(\mathrm{M}=6.96$; $\mathrm{SD}=0.80)$.

\subsubsection{Sleep and Mental Health}

A significant relationship between sleep and mental health was found. The PSQI and SCL-90-R correlated significantly ( $r=0.592 ; p<0.001)$. In a linear regression $35 \%$ of variance was detected. The scales PSDI (Positive Symptom Distress Index), depression and anxiety correlated significantly with the PSQI sum score, but not with all subscales as seen in Table 3. Linear regression showed the Positive Symptom Distress Index subscale explained $26 \%$ of PSQI variance $(\mathrm{F}(1,100)=35.942)$, the depression subscale $22 \%$ of the PSQI variance $(\mathrm{F}(1$, $100)=28.135 ; p=0.000)$ and anxiety $19 \%(\mathrm{~F}(1,100)=22.898 ; p=0.000)$.

But no significant correlations have been found between the SCL-90-Rs subscales and the sleep diary (all $p>$ $0.05)$.

\subsubsection{Sleep and Relationship}

A significant negative relationship between PSQI and PFB-K (Relationship satisfaction Questionnaire) was found $(r=-0.198 ; p=0.047$ ). This indicates low relationship quality is connected with low sleep quality. Higher scores on PFB-K resulted in lower PSQI scores, but only $4 \%$ of the variance was accounted for. A significant negative correlation between sleep medication and PFB-K $(r=-0.219 ; p=0.027)$ was found, but none for other PSQI subscales. For further details, see Table 4. 
Table 3. Correlations SCL-90-R (Sum score GSI, subscales PSDI, depression and anxiety) und PSQI.

\begin{tabular}{ccccccccccc}
\hline & \multicolumn{3}{c}{ GSI } & \multicolumn{2}{c}{ Positive Symptom } & \multicolumn{2}{c}{ Depression } & \multicolumn{2}{c}{ Anxiety } \\
\hline & $r$ & $p$ & $r$ & $p$ & $r$ & $p$ & $r$ & $p$ \\
\hline PSQI total score & 0.592 & $\mathbf{0 . 0 0 0}$ & 0.514 & $\mathbf{0 . 0 0 0}$ & 0.469 & $\mathbf{0 . 0 0 0}$ & 0.432 & $\mathbf{0 . 0 0 0}$ \\
PSQI.1 sleep quality & 0.504 & $\mathbf{0 . 0 0 0}$ & 0.468 & $\mathbf{0 . 0 0 0}$ & 0.353 & $\mathbf{0 . 0 0 0}$ & 0.306 & $\mathbf{0 . 0 0 2}$ \\
PSQI.2 sleep latency & 0.336 & 0.001 & 0.306 & $\mathbf{0 . 0 0 2}$ & 0.242 & 0.014 & 0.257 & $\mathbf{0 . 0 0 9}$ \\
PSQI.3 sleep duration & 0.208 & $\mathbf{0 . 0 3 6}$ & 0.140 & 0.163 & 0.142 & 0.157 & 0.167 & 0.094 \\
PSQI.4 sleep efficiency & 0.248 & $\mathbf{0 . 0 1 3}$ & 0.202 & $\mathbf{0 . 0 4 3}$ & 0.170 & 0.090 & 0.154 & 0.125 \\
PSQI.5 sleep disturbances & 0.515 & $\mathbf{0 . 0 0 0}$ & 0.517 & $\mathbf{0 . 0 0 0}$ & 0.418 & $\mathbf{0 . 0 0 0}$ & 0.393 & $\mathbf{0 . 0 0 0}$ \\
PSQI.6 sleep medication & 0.225 & $\mathbf{0 . 0 2 3}$ & 0.135 & 0.176 & 0.213 & $\mathbf{0 . 0 3 2}$ & 0.223 & $\mathbf{0 . 0 2 4}$ \\
PSQI.7 daytime sleepiness & 0.556 & $\mathbf{0 . 0 0 0}$ & 0.521 & $\mathbf{0 . 0 0 0}$ & 0.532 & $\mathbf{0 . 0 0 0}$ & 0.394 & $\mathbf{0 . 0 0 0}$ \\
\hline
\end{tabular}

Marked results are based on $p<0.05$.

Table 4. Correlations of PFB-K and PSQI subscales.

\begin{tabular}{|c|c|c|c|c|c|c|c|c|c|c|c|c|c|c|}
\hline & \multicolumn{2}{|c|}{ PFB-K } & \multicolumn{2}{|c|}{ Fighting } & \multicolumn{2}{|c|}{ Tenderness } & \multicolumn{2}{|c|}{ Comunality } & \multicolumn{2}{|c|}{ Hapiness Item } & \multicolumn{2}{|c|}{ Sex Importance } & \multicolumn{2}{|c|}{ Sex Satisfaction } \\
\hline & $r$ & $p$ & $r$ & $p$ & $r$ & $p$ & $r$ & $p$ & $r$ & $p$ & $r$ & $p$ & $r$ & $p$ \\
\hline $\begin{array}{c}\text { PSQI } \\
\text { sum score }\end{array}$ & 0.198 & 0.047 & 0.321 & 0.001 & 0.072 & 0.471 & 0.095 & 0.344 & 0.118 & 0.238 & 0.030 & 0.762 & 0.176 & 0.074 \\
\hline $\begin{array}{c}\text { PSQI.1 } \\
\text { sleep quality }\end{array}$ & 0.102 & 0.310 & 0.128 & 0.203 & 0.028 & 0.783 & 0.101 & 0.317 & 0.057 & 0.569 & 0.029 & 0.777 & 0.164 & 0.100 \\
\hline $\begin{array}{c}\text { PSQI.2 } \\
\text { sleep latency }\end{array}$ & 0.015 & 0.884 & 0.190 & 0.056 & 0.111 & 0.267 & 0.011 & 0.911 & 0.026 & 0.794 & 0.051 & 0.610 & 0.056 & 0.575 \\
\hline $\begin{array}{c}\text { PSQI.3 } \\
\text { sleep duration }\end{array}$ & 0.155 & 0.120 & 0.178 & 0.075 & 0.117 & 0.244 & 0.083 & 0.407 & 0.148 & 0.139 & 0.066 & 0.513 & 0.052 & 0.603 \\
\hline $\begin{array}{c}\text { PSQI.4 } \\
\text { sleep efficiency }\end{array}$ & 0.128 & 0.203 & 0.189 & 0.058 & 0.059 & 0.556 & 0.049 & 0.628 & 0.028 & 0.784 & 0.014 & 0.888 & 0.081 & 0.419 \\
\hline $\begin{array}{c}\text { PSQI.5 } \\
\text { sleep disturbances }\end{array}$ & 0.172 & 0.084 & 0.144 & 0.148 & 0.139 & 0.162 & 0.135 & 0.176 & 0.078 & 0.438 & 0.102 & 0.305 & 0.275 & 0.005 \\
\hline $\begin{array}{c}\text { PSQI.6 } \\
\text { sleep medication }\end{array}$ & 0.219 & 0.027 & 0.312 & 0.001 & 0.140 & 0.160 & 0.067 & 0.504 & 0.184 & 0.064 & 0.006 & 0.952 & 0.090 & 0.369 \\
\hline $\begin{array}{c}\text { PSQI.7 } \\
\text { daytime sleepiness }\end{array}$ & 0.083 & 0.405 & 0.237 & 0.016 & 0.030 & 0.764 & 0.000 & 0.997 & 0.072 & 0.475 & 0.024 & 0.810 & 0.086 & 0.388 \\
\hline
\end{tabular}

Marked results are based on $p<0.05$.

Sleep duration based on the sleep diary correlated significantly with the PFB-K score $(r=0.289 ; p=0.003)$. The PBF-K score explains $8 \%$ of the sleep durations variance, calculated by linear regression $(F(1,99)=9.020$, $p=.003)$. No other sleep diary parameters correlated with the PBF-K. The effect of PFB-K score on sleep duration is mediated by the participant's age (see Table 5). Shorter sleep durations and lower relationship quality are associated with higher age.

The PFB-K subscale, fighting behavior, correlated significantly with the PSQI sum score $(r==0.321 ; p=$ 0.001), suggesting couples who were fighting more often slept worse. In a linear regression $10 \%$ of PSQIs variance was explained by fighting behavior.

Furthermore, fighting measured on basis of the sleep diary showed a negative correlation with sleep latency ( $r$ $=-0.286, p=0.004)$. Fighting during the night led to shorter sleep durations $(r=0.202 ; p=0.043)$, whereas fighting during the day did not influence sleep duration ( $r=0.152 ; p=0.129$ ).

No significant correlation was found between satisfaction with sexual intercourse and the PSQI sum score $(r$ $=-0.176 ; p=0.074$ ) but the PSQI subscale sleep disturbances correlated significantly with inter course satisfaction $(r=-0.275 ; p=0.005)$. The more satisfied the participants were with sex the less sleep disturbances they 
reported, in a linear regression with $8 \%$ of variance explained.

To prove the theoretical Partnership-Emotional wellbeing-Sleep model (PES), contained influences on sleep disturbances by relationship quality, fighting and well-being (as seen in Figure 1) were tested. All variables showing a significant correlation with the PSQI sum score were included in this theoretical model. Gender and age had no significant influence in this model. Fighting partnership-behavior and mental health, measured by the GSI, significantly influenced sleep $(\mathrm{F}(2,99)=30.340 ; p=0.000$, see Table 6$)$. This model explains $38 \%$ of variance. But relationship satisfaction, anxiety and depression, failed to explain further variance within the model. This suggests that higher mental strain and dysfunctional fighting behavior impairs couple's sleep.

\section{Discussion}

In the present study a significant correlation of PSQI and PFB-K supports the association of sleep quality and relationship satisfaction. Previous studies showed that relationship quality predicted clinically relevant sleep disturbances. Women in a satisfying marriage experienced significantly fewer sleep problems than women in non-satisfying marriages [10]. In the present sample containing both men and women, similar findings suggest general mechanisms for both genders. Furthermore, the sample size in the present study is fairly good, compared to earlier studies in which sample sizes ranged between 46 couples [28] and 78 couples [8].

Sleep duration measured by the sleep diary correlated with relationship satisfaction. Age explains this link, as older people show shorter sleep durations and less relationship satisfaction [17] [24]. But in our sample with a wide range in age, subscales of either PSQI or PFB-K showed no correlations -except for sleep medication, which participants did not commonly take.

Table 5. Regression on relationship quality (PBF-K).

\begin{tabular}{cccc}
\hline Variable & Standardized Coefficients Beta & $\mathrm{t}$ & Sig. \\
\hline Age & -0.342 & -3.432 & 0.001 \\
Total sleep duration (sleep diary) & 0.151 & 1.516 & 0.133 \\
\hline
\end{tabular}

Regression coefficient $\mathrm{B}$, standard deviation and $\beta$ for variables in the model ${ }^{*} p<0.05 .{ }^{* *} p<0.001$.

Table 6. Regression on sleep problems (PSQI sum score).

\begin{tabular}{cccc}
\hline Variable & B & SE B & $\beta$ \\
\hline GSI & 0.156 & 1.602 & $0.545^{* *}$ \\
$\begin{array}{c}\text { PFB-K constructive } \\
\text { fighting behavior }\end{array}$ & -0.248 & 0.114 & $-0.179^{*}$ \\
\hline
\end{tabular}

Regression coefficient $\mathrm{B}$, standard deviation and $\beta$ for variables in the model ${ }^{*} p<0.05 .{ }^{* *} p<0.001$

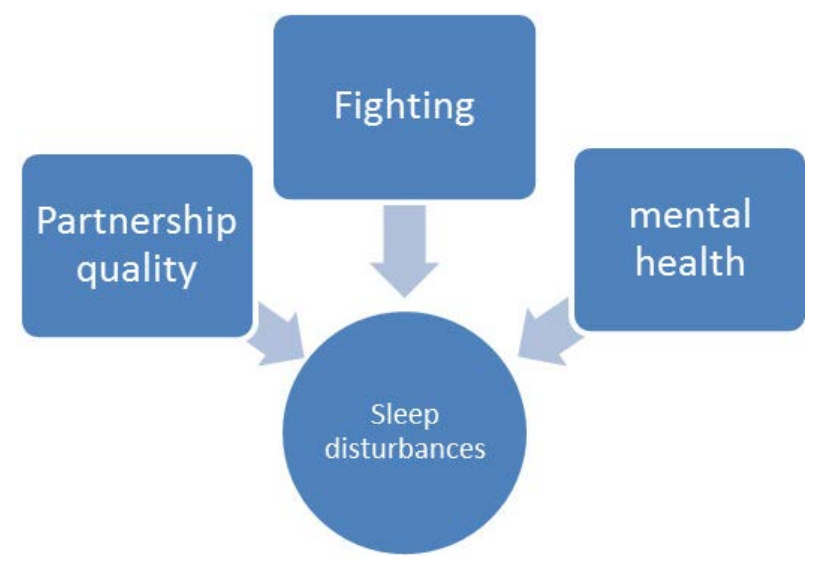

Figure 1. Theoretical model for sleep disturbances used for multiple regression. The Partnership-Emotional wellbeingSleep model (PES). 
In addition, we found an association between destructive fighting behaviour and sleep quality. This result is in line with earlier studies [12]-[14] showing that sarcastic criticism, accusing the partner of something and aspersions are associated with less sleep quality and more daytime sleepiness. Birditt and colleagues reported that destructive fighting behaviour is related to a higher divorce rate [16]. Based on these findings one may suggest that constructive fighting behaviour and therefore a higher relationship satisfaction could lead to higher sleep quality. When participants reported a fight, longer sleep latencies and shorter sleep duration appeared. According to ElSheikh and colleaguespsychological violence of women is correlated with more anxiety in their male partners [12]. Women showed longer sleep latency associated with the amount of psychological violence they used. Men's depression symptoms also lead to longer sleep latency in their partners. This association has also been shown vice versa: a poor night's sleep leads to more destructive fighting and less accurate empathetic reactions [29].

In our sample, satisfaction with sexual life correlated negatively with sleep disturbances. This suggests that couples who were satisfied with their sexual intercourse suffered from less sleep disturbances. Furthermore, participants reported a better mood when they had sex during the night. Supported is this finding by Ditzen and colleagues who stated intimacy alleviates stress [30]. Stress is known to have a negative impact on sleep [31] and might mediate the influence of sexual intercourses on sleep.

In a multiple regression model fighting and mental strain explained 38\% of sleep quality variance. Depression, anxiety and relationship quality showed no further improvement of the model. Other factors-like attachment style - which were not considered in this study might improve the model, as Carmichael and Reisfound a higher fear of attachment to be associated with poor sleep quality in couples [8].

Consistent with findings by Schlack and colleagues we found a decrease in sleep duration with higher age [24]. Despite shorter sleep durations, daytime sleepiness decreased as well with higher age in the present sample. Studies suggest that older people take more daytime naps and therefore feel fitter [32]. Participants younger than-compared to those older than 40-did not report more trouble to fall or stay asleep. This finding contradicts Schlack and colleagues, suggesting that 40 years might not be an appropriate split point. But our sample does not provide a new split point, either.

In the present sample gender differences in sleep were only partly found. Women showed an equal number of sleep disturbances compared to men, contrary to earlier findings of more sleep disturbances in women [33] [34]. Nevertheless, sleep diary data showed a longer sleep onset latency of five minutes in mean for women. Furthermore, women slept longer than men. Van den Berg and colleagues found women slept 16 minutes longer than men. Women in the present sample slept 18 minutes longer [35]. Besides, sleep satisfaction did not differ in this sample, contrary to earlier studies [24] [35]. As another study consisted of people aged 68.4 in mean, age might be a possible explanation. Older women might be less satisfied with their sleep than men of the same age.

In addition, mental strain (measured by GSI) and sleep quality (measured by PSQI) correlated significantly positively, supporting earlier findings. Therefore, mental strains are associated with sleep disturbances and a lower sleep quality, like Taylor and colleagues stated [18]. Zawadzki and colleagues also found an association between sleep and mood [21]. Only depression and sleep onset latency were associated in our study, while no association of depression and sleep efficiency was found. Other studies suggest a general relationship between depression and sleeping problems [20] [36] [37]. Anxiety is linked to sleeping problems, in our sample as well as other studies [18] [20].

However, some limitations should be named. Intimate topics like sexuality and fighting in relationships might methodologically limit this study. Further anonymity-possibly through online questionnaires-might improve following studies about this topic. In addition, this sample did not show a continuous distribution of age. Longitudinal studies could determine causalities for underlying mechanisms. Additionally, intervention-studies concerning destructive fighting behaviour can give further information. Following studies should implement more couples which might help detect more underlying mechanisms.

\section{Conclusions}

In this study, subjective sleep quality and relationship satisfaction significantly correlated. In the theoretical Partnership-Emotional wellbeing-Sleep model (PES) higher relationship quality, better mental health and fewer conflicts in a relationship were associated with better sleep quality.

Conflicts often led to longer sleep latency and less sleep duration. Nevertheless the association of overall rela- 
tionship quality and sleep quality was moderated by age, as older participants slept worse and were less satisfied with their relationships.

Sexual intercourses were another important factor influencing sleep quality. Intercourse at night led to a better mood in the morning.

These findings underlined that intimate relationships were important for sleep quality and vice versa. Therefore, relationship quality should always be taken into account and be asked for in adults suffering from sleep problems.

\section{References}

[1] Hinz, A., Stöbel-Richter, Y. and Brähler, E. (2001) Der Partnerschaftsfragebogen (PFB). Diagnostica, 47, $132-141$. http://dx.doi.org/10.1026//0012-1924.47.3.132

[2] Hale, L. (2005) Who Has Time to Sleep? Journal of Public Health (Oxford, England), 27, 205-211. http://dx.doi.org/10.1093/pubmed/fdi004

[3] Troxel, W.M., Buysse, D.J., Matthews, K.A., Kravitz, H.M., Bromberger, J.T., Sowers, M. and Hall, M.H. (2010) Marital/Cohabitation Status and History in Relation to Sleep in Midlife Women. Sleep, 33, 973-981.

[4] Hamilton, N.A., Gallagher, M.W., Preacher, K.J., Stevens, N., Nelson, C.A., Karlson, C. and McCurdy, D. (2007) Insomnia and Well-Being. Journal of Consulting and Clinical Psychology, 75, 939-946. http://dx.doi.org/10.1037/0022-006X.75.6.939

[5] Yang, H, Suh, S., Kim, H., Cho, E.R., Lee, S.K. and Shin, C. (2013) Testing Bidirectional Relationships between Marital Quality and Sleep Disturbances: A 4-Year Follow-Up Study in a Korean Cohort. Journal of Psychosomatic Research, 74, 401-406. http://dx.doi.org/10.1016/j.jpsychores.2013.01.005

[6] Grandner, M.A., Patel, N.P., Gehrman, P.R., Xie, D., Sha, D., Weaver, T. and Gooneratne, N. (2010) Who Gets the Best Sleep? Ethnic and Socioeconomic Factors Related to Sleep Complaints. Sleep Medicine, 11, 470-478. http://dx.doi.org/10.1016/j.sleep.2009.10.006

[7] Hasler, B.P. and Troxel, W.M. (2010) Couples’ Nighttime Sleep Efficiency and Concordance: Evidence for Bidirectional Associations with Daytime Relationship Functioning. Psychosomatic Medicine, 72, 794-801. http://dx.doi.org/10.1097/PSY.0b013e3181ecd08a

[8] Carmichael, C.L. and Reis, H.T. (2005) Attachment, Sleep Quality, and Depressed Affect. Health Psychology Official Journal of the Division of Health Psychology, American Psychological Association, 24, 526-531.

[9] Diamond, L.M., Hicks, A.M. and Otter-Henderson, K.D. (2008) Every Time You Go Away: changes in Affect, Behavior, and Physiology Associated with Travel-Related Separations from Romantic Partners. Journal of Personality and Social Psychology, 95, 385-403. http://dx.doi.org/10.1037/0022-3514.95.2.385

[10] Troxel, W.M., Buysse, D.J., Hall, M. and Matthews, K.A. (2009) Marital Happiness and Sleep Disturbances in a Multi-Ethnic Sample of Middle-Aged Women. Behavioral Sleep Medicine, 7, 2-19. http://dx.doi.org/10.1080/15402000802577736

[11] Cacioppo, J.T., Hawkley, L.C., Berntson, G.G., Ernst, J.M., Gibbs, A.C., Stickgold, R. and Hobson, J.A. (2002) Do Lonely Days Invade the Nights? Potential Social Modulation of Sleep Efficiency. Psychological Science, 13, 384-387. http://dx.doi.org/10.1111/j.0956-7976.2002.00469.x

[12] El-Sheikh, M., Kelly, R. and Rauer, A. (2013) Quick to Berate, Slow to Sleep: Interpartner Psychological Conflict, Mental Health, and Sleep. Health Psychology, 32, 1057-1066. http://dx.doi.org/10.1037/a0031786

[13] Rauer, A.J., Kelly, R.J., Buckhalt, J.A. and El-Sheikh, M. (2010) Sleeping with One Eye Open: Marital Abuse as an Antecedent of Poor Sleep. Journal of Family Psychology, 24, 667-677. http://dx.doi.org/10.1037/a0021354

[14] Rauer, A.J. and El-Sheikh, M. (2012) Reciprocal Pathways between Intimate Partner Violence and Sleep in Men and Women. Journal of Family Psychology, 26, 470-477. http://dx.doi.org/10.1037/a0027828

[15] Orbuch, T.L., Veroff, J., Hassan, H. and Horrocks, J. (2002) Who Will Divorce: A 14-Year Longitudinal Study of Black Couples and White Couples. Journal of Social and Personal Relationships, 19, 179-202. http://dx.doi.org/10.1177/0265407502192002

[16] Birditt, K.S., Brown, E., Orbuch, T.L. and McIlvane, J.M. (2010) Marital Conflict Behaviors and Implications for Divorce over 16 Years. Journal of Marriage and the Family, 72, 1188-1204. http://dx.doi.org/10.1111/j.1741-3737.2010.00758.x

[17] Klaiberg, A., Würz, J., Brähler, E. and Schumacher, J. (2001) Influences on Satisfaction with Sexuality and Partnership in Women. Der Gynäkologe, 34, 259-269. http://dx.doi.org/10.1007/s001290050711

[18] Taylor, D.J., Lichstein, K.L., Durrence, H.H., Reidel, B.W. and Bush, A.J. (2005) Epidemiology of Insomnia, Depres- 
sion, and Anxiety. Sleep, 28, 1457-1464.

[19] Soehner, A.M. and Harvey, A.G. (2012) Prevalence and Functional Consequences of Severe Insomnia Symptoms in Mood and Anxiety Disorders: Results from a Nationally Representative Sample. Sleep, 35, 1367-1375. http://dx.doi.org/10.5665/sleep.2116

[20] Neckelmann, D., Mykletun, A. and Dahl, A.A. (2007) Chronic Insomnia as a Risk Factor for Developing Anxiety and Depression. Sleep, 30, 873-880.

[21] Zawadzki, M.J., Graham, J.E. and Gerin, W. (2013) Rumination and Anxiety Mediate the Effect of Loneliness on Depressed Mood and Sleep Quality in College Students. Health Psychology, 32, 212-222. http://dx.doi.org/10.1037/a0029007

[22] Vahtera, J., Kivimaki, M., Hublin, C., Korkeila, K., Suominen, S., Paunio, T. and Koskenvuo, M. (2007) Liability to Anxiety and Severe Life Events as Predictors of New-Onset Sleep Disturbances. Sleep, 30, 1537-1546.

[23] Morin, C.M., Rodrigue, S. and Ivers, H. (2003) Role of Stress, Arousal, and Coping Skills in Primary Insomnia. Psychosomatic Medicine, 65, 259-267. http://dx.doi.org/10.1097/01.PSY.0000030391.09558.A3

[24] Schlack, R., Hapke, U., Maske, U., Busch, M. and Cohrs, S. (2013) Häufigkeit und Verteilung von Schlafproblemen und Insomnie in der deutschen Erwachsenenbevölkerung: Ergebnisse der Studie zur Gesundheit Erwachsener in Deutschland (DEGS1). Bundesgesundheitsblatt, Gesundheitsforschung, Gesundheitsschutz, 56, 740-748. http://dx.doi.org/10.1007/s00103-013-1689-2

[25] Buysse, D.J., Reynolds, C.F., Monk, T.H., Berman, S.R. and Kupfer, D.J. (1989) The Pittsburgh Sleep Quality Index: A New Instrument for Psychiatric Practice and Research. Psychiatry Research, 28, 193-213. http://dx.doi.org/10.1016/0165-1781(89)90047-4

[26] Kliem, S., Job, A., Kröger, C., Bodenmann, G., Stöbel-Richter, Y., Hahlweg, K. and Brähler, E. (2012) Entwicklung und Normierung einer Kurzform des Partnerschaftsfragebogens (PFB-K) an einer repräsentativen deutschen Stichprobe. Zeitschrift für Klinische Psychologie und Psychotherapie, 41, 81-89. http://dx.doi.org/10.1026/1616-3443/a000135

[27] Hessel, A., Schumacher, J., Geyer, M. and Brähler, E. (2001) Symptom-Checkliste SCL-90-R. Diagnostica, 47, 27-39. http://dx.doi.org/10.1026//0012-1924.47.1.27

[28] Kane, H.S., Slatcher, R.B., Reynolds, B.M., Repetti, R.L. and Robles, T.F. (2014) Daily Self-Disclosure and Sleep in Couples. Health Psychology, 33, 813-822. http://dx.doi.org/10.1037/hea0000077

[29] Gordon, A.M. and Chen, S. (2014) The Role of Sleep in Interpersonal Conflict: Do Sleepless Nights Mean Worse Fights? Social Psychological and Personality Science, 5, 168-175. http://dx.doi.org/10.1177/1948550613488952

[30] Ditzen, B., Hoppmann, C. and Klumb, P. (2008) Positive Couple Interactions and Daily Cortisol: On the StressProtecting Role of Intimacy. Psychosomatic Medicine, 70, 883-889. http://dx.doi.org/10.1097/PSY.0b013e318185c4fc

[31] Paulsen, V.M. and Shaver, J.L. (1991) Stress, Support, Psychological States and Sleep. Social Science \& Medicine, 32, 1237-1243.

[32] Neubauer, D.N. (1999) Sleep Problems in the Elderly. American Family Physician, 59, 2551-2560.

[33] Zhang, B. and Wing, Y. (2006) Sex Differences in Insomnia: A Meta-Analysis. Sleep, 29, 85-93.

[34] Ohayon, M.M. (2002) Epidemiology of Insomnia: What We Know and What We Still Need to Learn. Sleep Medicine Reviews, 6, 97-111. http://dx.doi.org/10.1053/smrv.2002.0186

[35] van den Berg, J.F., Miedema, H.M.E., Tulen, J.H.M., Hofman, A., Neven, A.K. and Tiemeier, H. (2009) Sex Differences in Subjective and Actigraphic Sleep Measures: A Population-Based Study of Elderly Persons. Sleep, 32, 13671375.

[36] Heilemann, M.V., Choudhury, S.M., Kury, F.S. and Lee, K.A. (2012) Factors Associated with Sleep Disturbance in Women of Mexican Descent. Journal of Advanced Nursing, 68, 2256-2266. http://dx.doi.org/10.1111/j.1365-2648.2011.05918.x

[37] Brabbins, C.J., Dewey, M.E., Copeland, J.R.M., Davidson, I.A., McWilliam, C., Saunders, P., Sharma, V.K. and Sullivan, C. (1993) Insomnia in the Elderly: Prevalence, Gender Differences and Relationships with Morbidity and Mortality. International Journal of Geriatric Psychiatry, 8, 473-480. http://dx.doi.org/10.1002/gps.930080604 